\title{
A survey of sharps injuries and occupational infections among healthcare workers in Shanghai
}

\author{
Jiabing Lin ${ }^{1}$, Xiaodong Gao ${ }^{1}$, Yangwen Cui ${ }^{1}$, Wei Sun ${ }^{1}$, Yan Shen ${ }^{1}$, Qingfeng Shi ${ }^{1}$, Xiang Chen ${ }^{1}$, \\ Bijie $\mathrm{Hu}^{1,2}$
}

${ }^{1}$ Department of Hospital Infection Management, ${ }^{2}$ Department of Infectious Diseases, Zhongshan Hospital, Fudan University, Shanghai 200032, China

Contributions: (I) Conception and design: X Gao, B Hu, J Lin; (II) Administrative support: X Gao, B Hu; (III) Provision of study materials or patients: Y Cui, W Sun, Y Shen; (IV) Collection and assembly of data: J Lin, Q Shi, X Chen; (V) Data analysis and interpretation: J Lin, X Gao; (VI) Manuscript writing: All authors; (VII) Final approval of manuscript: All authors.

Correspondence to: Dr. Xiaodong Gao. Department of Hospital Infection Management, Zhongshan Hospital, Fudan University, 180 Fenglin Road, Shanghai 200032, China. Email: gaoxd5@vip.sina.com; Dr. Bijie Hu. Department of Infectious Diseases, Department of Hospital Infection Management, Zhongshan Hospital, Fudan University, 180 Fenglin Road, Shanghai 200032, China.

Email: hubijie@vip.sina.com; hu.bijie@zs-hospital.sh.cn.

Background: Healthcare workers (HCWs) are at greater risk of occupational exposure to sharp injuries in their daily routine work, which is extremely worrying due to the potential risk of transmitting bloodborne pathogens. This study aims to assess what procedures and factors present the greatest risk of sharp injuries to HCWs in Shanghai and to provide an evidence base for improving measures to reduce sharps injuries.

Methods: A cross-sectional study was administered to all HCW who might be exposed to sharp instruments in 81 hospitals in Shanghai. According to the voluntary, investigate as many HCWs as possible and get feedbacks $N=61,309$. The survey addressed the sharp injury (SI) incidents, SIs of common instruments, SIs of common locations, SIs of operating procedures, SIs of common instruments and common sources of SI occurrences. Statistical analysis was performed using the SPSS program.

Results: A total of 61,309 HCWs were surveyed for this study, and 935 (1.53\%) HCWs experienced the various types of sharp injuries in one month. Of the 1,140 sharp injuries, 292 (25.61\%) sharp injuries were reported, and $815(71.49 \%)$ sharp injuries were traced to their sources. Interns experienced the highest proportion of sharps injuries $(4.12 \%)$. General wards were the most common location where sharp injuries occurred to HCWs (36.05\%), while disposable syringes were the most common medical devices that caused sharp injuries $(32.11 \%)$. Nurses, doctors and logistical workers who did not receive relevant training had a higher incidence of SI $(4.40 \%, 4.95 \%$ and $4.03 \%$, respectively) than those who received training $(1.58 \%$, $1.03 \%$ and $0.67 \%$, respectively, $\mathrm{P}<0.001)$. HBV infection was the main source of exposure to sharp injuries, with scalpel cuts being the most common related occurrence.

Conclusions: Sharp injuries occur among HCWs in Shanghai dented optimism. There are multiple highrisk factors for SI and exposure to blood-borne pathogens in their work such as interns, general wards, disposable syringes, and lack of relevant training. HBV infection was the main source of exposure to sharp injuries. As such, medical institutions shall pay closer attention to this topic.

Keywords: Healthcare workers (HCWs); sharps injuries; occupational infection; current situation analysis; incidence rates; risk factors

Submitted Jul 27, 2019. Accepted for publication Sep 27, 2019.

doi: $10.21037 /$ atm.2019.10.42

View this article at: http://dx.doi.org/10.21037/atm.2019.10.42 


\section{Introduction}

In their everyday work, healthcare workers (HCWs) often face occupational hazards due to continuous exposure to contaminated sharps injuries and subsequent exposure to blood-borne diseases, such as HBV, HCV and HIV. Sharp injuries are considered an important occupational hazard for HCWs (1). The Centers for Disease Control and Prevention (CDC) estimates that in the United States, as many as $384,325 \mathrm{HCW}$ s are exposed to blood and body fluids through acute and skin injuries each yea $(2,3)$, 600,000 needlestick injuries (NSIs) occur annually, and half of these injuries to HCWs remain unreported (4). A 2014 multi-centre study from China showed that the incidence of sharp injuries among Chinese HCWs was significantly above the international level (5). Shanghai, a metropolis with many top-class medical disciplines, is home to a larger number of HCWs compared with other cities in China. Furthermore, hospitals in Shanghai admit more patients with difficult, complicated and critical diseases from all over the country. As a result, the chances of treating critical patients and operating with complicated sharp instruments are greatly increased. HCWs in Shanghai are more prone to exposure to sharp injuries. We conducted this study to learn more about the incidence of sharp injuries and occupational nosocomial infections among HCWs in Shanghai.

\section{Methods}

\section{Subjects of survey}

In this study, all HCWs who might be exposed to sharp instruments in 81 grade A secondary and tertiary hospitals in Shanghai were the subjects of the survey, which included their job categories, such as doctors, nurses, logistical workers, medical technicians, and interns.

\section{Time and contents of survey}

In July 2016, a self-prepared questionnaire was used to survey the incidence of sharp injuries in 81 hospitals in Shanghai. The questionnaire was aimed to investigate the sharp injury (SI) occurrence in June and covered the following aspects: (I) basic situation of sharp injuries among HCWs; (II) sharp injuries among HCWs in the same job categories; (III) common locations of sharp injuries to HCWs; (IV) sharp injuries among HCWs occurring during different medical procedures; (V) common medical devices causing sharp injuries to HCWs; (VI) sharp injuries among HCWs with different lengths of service; (VII) sharp injuries among HCWs with different levels of training; (VIII) sources of exposure to infection in hospitals of different grades, including hepatitis B, hepatitis C, HIV and syphilis; (IX) operating procedures causing sharp injuries to HCWs at different common locations; (X) operating procedures using different common devices causing sharp injuries to HCWs; (XI) operating procedures causing sharp injuries in HCWs with different lengths of service; and (XII) operating procedures causing SI infection from different sources of exposure to infection.

\section{Method of survey}

The online questionnaire survey was created in Shanghai by the Shanghai Nosocomial Infection Control Center. Before the survey started in July 2016, the Shanghai Nosocomial Infection Control Center provided unified training to the persons in charge at the surveyed hospitals. Personnel at the Shanghai Nosocomial Infection Control Center collected, checked and sorted the completed questionnaires. Questionnaire integrity and logicality were also checked.

\section{Statement of ethics approval}

This study is a cross-sectional investigation confined only to the sharp injuries relevant information among HCWs only. It does not involve any collection of human or animal samples therefore do not involve ethics approval. The authors are accountable for all aspects of the work in ensuring that questions related to the accuracy or integrity of any part of the work are appropriately investigated and resolved.

\section{Computation method and statistical analysis}

After the results were uniformly exported and reviewed, SPSS 20.0 software was used for statistical analysis with rates or constituent ratios adopted for statistical description. Median and interquartile range $\mathrm{P}_{50}\left(\mathrm{P}_{25}, \mathrm{P}_{75}\right)$ were used for the statistical description of non-normally distributed data, while the $\chi^{2}$ test was used for data comparison. Detailed calculations of correlation ratios can be found in the notes to each table. 
Table 1 Sharp injury (SI) incidents and reporting rates among HCWs

\begin{tabular}{|c|c|c|c|c|c|c|c|}
\hline Job category & $\mathrm{N}$ & $\begin{array}{l}\text { Number of SI } \\
\text { incidents }(\%)^{\star}\end{array}$ & $\begin{array}{l}\text { Total number of } \\
\text { SI incidents }\end{array}$ & $\begin{array}{l}\text { SI incidents } \\
\text { per } 1,000 \text { persons } \\
\text { per month }\end{array}$ & $\begin{array}{l}\text { SI incidents per } 100 \\
\text { patient beds per month }\end{array}$ & $\begin{array}{l}\text { Reported } \\
\text { cases }(\%)^{*}\end{array}$ & $\begin{array}{c}\text { Source patient } \\
\text { known }(\%)^{*}\end{array}$ \\
\hline Doctors & 19,927 & 268 (1.34) & 327 & 16.41 & 0.52 & $79(24.16)$ & $251(76.76)$ \\
\hline Logistical workers & 3,583 & $28(0.78)$ & 31 & 8.65 & 0.05 & 15 (48.39) & $6(19.35)$ \\
\hline Interns & 1,458 & $60(4.12)$ & 72 & 49.38 & 0.11 & $36(50.00)$ & $50(69.44)$ \\
\hline Others & 316 & $2(0.63)$ & 4 & 12.66 & 0.01 & $0(0.00)$ & $0(0.00)$ \\
\hline Total & 61,309 & 935 (1.53) & 1,140 & 18.59 & 1.81 & $292(25.61)$ & 815 (71.49) \\
\hline
\end{tabular}

${ }^{*}, \mathrm{P}<0.001$ Number of $\mathrm{SI}$ incidents = number of $\mathrm{SI}$ incidents/number of persons surveyed $\times 100 \%$. SI incidents per 1,000 persons $=$ total number of $\mathrm{SI}$ incidents/number of persons surveyed $\times 1,000$. SI incidents per 1,000 beds = total number of SI incidents/sum of beds of all surveyed hospitals $\times 100 \%$. Reporting rate $=$ reported cases/total number of SI incidents $\times 100 \%$. The rate of source patient known $=$ source patient known cases/total number of SI incidents $\times 100 \%$. SI, sharp injury; HCW, healthcare worker.

\section{Results}

\section{Basic information about the surveyed hospitals}

In July 2016, a survey was conducted among all HCWs who might be exposed to sharp instruments at 81 hospitals in Shanghai. The basic information about the hospitals in which the subjects of the survey were located is shown in Table S1.

\section{Incidence of sharp injuries among HCWs by professional group}

A total of $61,309 \mathrm{HCW}$ s were surveyed in this study, and 935 (1.53\%) HCWs suffered sharp injuries. There were 1,140 sharp injuries in total, with 292 (25.61\%) sharp injuries reported and 815 (71.49\%) sharp injuries traced to their sources.

There were statistically significant differences in the number of sharp injuries among HCWs in different job categories, with interns accounting for the highest proportion of HCWs who received sharp injuries. After the occurrence of sharp injuries, the reporting rates among different job categories also showed statistically significant differences, with interns having the highest reporting rate. Moreover, the differences in the traceability of sharp injuries among different job categories were statistically significant, with doctors having the highest traceability rate, as detailed in Table 1 .

\section{Common locations of sharp injuries}

According to the survey results, the general ward was the most common location of sharp injuries to HCWs. Table 2 shows details of the occurrence of sharp injuries in different job categories.

\section{Common procedures causing sharp injuries}

The survey results showed that the most common operating procedure causing sharp injuries was rehydration configuration for injection for nurses; scalpel cuts or surgical suture for doctors; sorting out used syringe needles or devices at medical waste site for logistical workers; replacing needle caps (recapping), putting syringe needles back in sharps boxes during disposal and drawing blood for medical technicians; and replacing needle caps (recapping) for interns, as detailed in Table 3.

\section{Common devices causing sharp injuries}

The survey results showed that disposable syringes were the most common devices causing sharp injuries to HCWs. Specifically, the most common devices causing sharp injuries were disposable syringes for nurses, surgical suture needles for doctors, and disposable syringes for both logistical workers and medical technicians. For interns, the most common devices causing sharp injuries involved disposable 


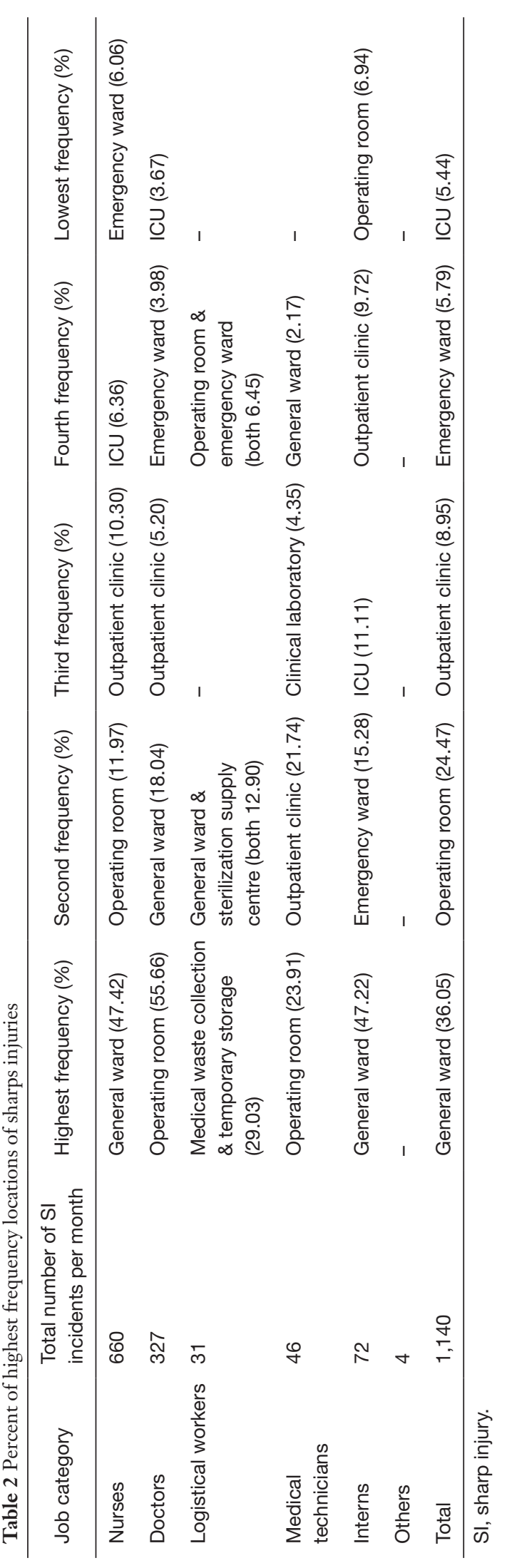

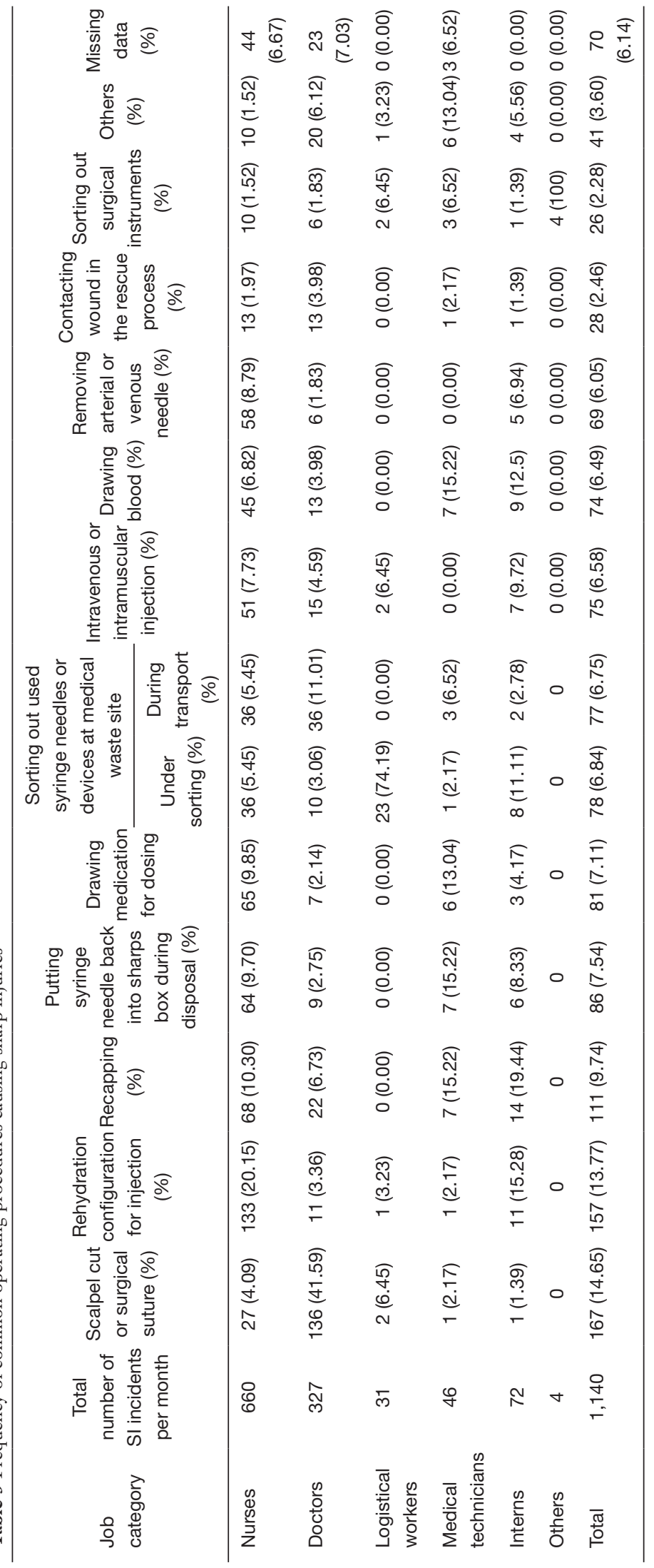


Table 4 Frequency of sharp injuries by status of training

\begin{tabular}{|c|c|c|c|c|c|c|c|c|}
\hline Job category & \multicolumn{3}{|c|}{ With training } & \multicolumn{3}{|c|}{ Without training } & $\chi^{2}$ & $P$ \\
\hline Nurses & 30,682 (98.42) & $494(1.58)$ & 31,176 & $500(95.6)$ & $23(4.40)$ & 523 & 25.372 & $<0.001$ \\
\hline Doctors & $18,173(98.97)$ & 189 (1.03) & 18,362 & 1095 (95.05) & $57(4.95)$ & 1,152 & 133.725 & $<0.001$ \\
\hline Logistical workers & 3,571 (99.33) & $24(0.67)$ & 3,595 & $238(95.97)$ & $10(4.03)$ & 248 & 29.951 & $<0.001$ \\
\hline Interns & $1,177(95.77)$ & $52(4.23)$ & 1,229 & $119(96.75)$ & $4(3.25)$ & 123 & 0.270 & 0.603 \\
\hline Others & $272(99.27)$ & $2(0.73)$ & 274 & $35(100.00)$ & $0(0.00)$ & 35 & 0.257 & 0.612 \\
\hline Missing data & 18 & $0(0.00)$ & 18 & $0(0.00)$ & $0(0.00)$ & $0(0.00)$ & - & - \\
\hline Total & 57,241 (98.64) & $788(1.36)$ & 58,029 & $2,126(95.77)$ & $94(4.23)$ & 2,220 & 122.631 & $<0.001$ \\
\hline
\end{tabular}

*, the composition ratio of sharp injury in different training situations = the number of no sharp injury or sharp injury/the total number with or without training $\times 100 \%$.

syringes and steel scalp needles, as shown in Table $S 2$.

\section{Sharp injuries by length of service}

The survey results showed that nurses, doctors, logistical workers, medical technicians, interns and workers in other job categories with a service length of less than 5 years were more prone to sharp injuries. The overall incidence of sharp injuries among HCWs showed a downward trend as their length of service increased, as shown in Table $S 3$.

\section{Sharp injuries among HCWs by training status}

The study results showed that nurses who did not receive training on prevention of occupational injury had a higher incidence of sharp injuries than nurses who received training. See details in Table 4.

\section{Procedures prone to occupational nosocomial infection from a $S I$}

The study results showed that scalpel cut or surgical suturing procedure was the most common source of exposure to hepatitis B and syphilis infections, while sources of exposure to hepatitis $\mathrm{C}$ infection were most likely to occur during recapping needles, as shown in Table 5.

\section{Discussion}

Despite progress in understanding occupational hazards to HCWs and the infections HCWs acquired from sharp injuries, occupational hazards remain a major public health issue worldwide. More attention should be paid to sharp injuries, an important source of occupational hazards to $\mathrm{HCWs}$, since the risk associated with direct exposure to blood-borne disease is high. These injuries not only raise the possibility of negative health consequences, but also lead to psychological distress which results in a direct negative effect on the health care service (6) and impose a high cost on the health care system as well (7). This study aimed to assess the incidence of sharp injuries and the subsequent occupational nosocomial infections among HCWs in Shanghai.

SIs among HCWs in Shanghai is similar to countries such as Serbia or hospital in Germany $(8,9)$. Our study results showed that interns, followed by nurses, had the highest SI incident rates. Based on the survey results, this finding is due to the higher likelihood that as a professional group, interns are more inexperienced and have fewer years of experience and training. However, after sustaining a SI, interns had the highest frequency of self-reports to occupational or employee health. All other categories of HCWs had a low reporting rate $(48.39 \%, 25.61 \%, 24.16 \%$ $23.03 \%, 21.74 \%$ to $50 \%$ ) after sharp injuries occurred.

This study shows that our HCWs, especially full-time workers, still do not have a sufficient understanding of the risks involved in sharp injuries and the urgency of reporting them a timely manner so that post-exposure follow-up can be performed. They also need to pay more attention to reporting and improving occupational behaviors such as 
Table 5 Frequency of procedures prone to be involved in occupational nosocomial infection from a sharp injury*

\begin{tabular}{|c|c|c|c|c|c|}
\hline Variable & Hepatitis B (\%) & Hepatitis C (\%) & HIV (\%) & Syphilis (\%) & Total (\%) \\
\hline Medical waste in disposal & $4(4.65)$ & $0(0.00)$ & $1(50.00)$ & $2(8.00)$ & 7 (5.69) \\
\hline Scalpel cut or surgical suture & $21(24.42)$ & $2(20.00)$ & $0(0.00)$ & $8(32.00)$ & $31(25.20)$ \\
\hline Replacing needle cap & $4(4.65)$ & $3(30.00)$ & $0(0.00)$ & $6(24.00)$ & $13(10.57)$ \\
\hline Contacting wound in the rescue process & $8(9.30)$ & $0(0.00)$ & $0(0.00)$ & $1(4.00)$ & $9(7.32)$ \\
\hline Drawing blood & $8(9.30)$ & $0(0.00)$ & $0(0.00)$ & $3(12.00)$ & $11(8.94)$ \\
\hline Sorting out surgical instruments & $5(5.81)$ & $0(0.00)$ & $0(0.00)$ & $1(4.00)$ & $6(4.88)$ \\
\hline Syringe needle or device transmission & $9(10.47)$ & $0(0.00)$ & $0(0.00)$ & $0(0.00)$ & $9(7.32)$ \\
\hline Total & 86 (69.92) & $10(8.13)$ & 2 (1.63) & 25 (20.33) & 123 \\
\hline
\end{tabular}

${ }^{*}$, the composition ratio of different operational processes in pathogen infection $=$ the number of infections with a certain pathogen that occurs in a certain operational procedure/the total number of infections of this pathogen $\times 100 \%$.

avoiding recapping the needles (10). The results suggest that it is necessary for HCWs to establish awareness of the importance of reporting SI incidents and to initiate post-exposure protocols so that timely detection and postexposure prevention can be carried out $(11,12)$.

Once a SI occurs, injuries to doctors are the easiest to trace back to a source patient, while the most difficult to trace are those to logistical workers. Logistical workers are not providing direct patient care and are thus exposed to contaminated sharps further downstream. As a result, good protective measures need to be in place, including safe disposal, use of safer medical devices and other engineering controls as well as paying close attention to work practices $(11,13)$.

Our study also serves as a reminder that no occupational protection can be ignored for any type of HCW. Providing timely consultation service to all HCWs after they suffer sharp injuries and encouraging them to report their cases and receive follow-up visits are essential (14).

This study illustrates that different job categories are more prone to different types of injuries based on the procedures they perform and the devices they use. Exercising targeted prevention and control over the most common procedures is the first step in preventing injuries. The implementation of strict prevention measures after the accidents reported allowed the significant reduction in the following year (15). Injury reporting and ongoing surveillance are important steps in identifying these interventions, so that facilities know where the injuries are occurring, with what devices, during what procedures, and to what professional groups. Other relevant studies have also suggested that targeted protective education should be carried out in accordance with the characteristics of each job category, emphasizing the location and procedures involved in sharp injuries in the course of work for each specific group $(16,17)$.

HCWs with a service length of less than 5 years are most prone to sharp injuries, and the incidence of sharp injuries shows a downward trend with increasing length of service. This finding is consistent with a previous study (5). People with less than 5 years of service tend to be new HCWs or interns. At such a length of service, they are often more focused on the development of their professional competency and less on the importance of their own self-protection.

However, we also noticed that doctors in the position of chief physicians and who have worked for over 30 years showed a slight rebound in the incidence of sharp injuries. In other words, after becoming a chief physician, doctors may become more confident in their medical operations, thereby compromising their own self-protection. This phenomenon results in an increased chance of sharp injuries and serves as a reminder that whether HCWs have become experienced medical personnel or not, they need to always 
maintain alertness to prevent injuries and exposures.

Our study results show that the incidence of sharp injuries among nurses, doctors and logistical workers without training are higher than the incidence among those who have received occupational protection training. The training must include the initial training at least. Other published studies also suggest that specific safety precautions and basic infection prevention training in hospitals can improve the operational safety of HCWs, thus reducing the occurrence of sharp injuries $(18,19)$. In a study on training of European medical personnel pointed out training has a spectacular impact on prevention and economic benefits improvement of SIs (20). Besides, reeducation of the HCWs also been proposed. Education specialists can provide educational activities to personnel to improve the knowledge and skills necessary to deal with this problem by different methods such as seminars, informative educational boards, pamphlets, and workshops $(21,22)$. However, we also noticed that the training does not seem to have achieved the desired results among interns with high incidences of sharp injuries, which may be due to their lack of awareness of the hazards of sharp injuries at this stage of their clinical experience. This observation also reminds us that in training such populations of professionals, trainers should adjust the training to match the level of self-awareness and experience with self-protection, use of engineering controls, and proficiency with work practice controls so that training is effective.

This study identified hepatitis B infection as the main source of infection risk during a SI in both tertiary and secondary hospitals. This finding is due to the large number of patients with hepatitis B in China, thus resulting in a significant increase in the risk of exposure to and infection with hepatitis B. However, we also noticed that during the month of our survey, two HIV infection cases were reported. Although $\mathrm{HIV}$ is a less likely occupational nosocomial infection than other blood-borne pathogens, the stigma, physical and psychological trauma associated with this disease is especially notable for HCWs and their families $(23,24)$.

We also noticed that among the procedures prone to be involved in occupational nosocomial infection from a SI, $\mathrm{HBV}$ infection occurred first, yet $\mathrm{HCV}$ infection could not be ignored. It is estimated that two million injuries cause approximately 16,000 $\mathrm{HCV}$ infections among 35 million HCWs each year (25). The availability of an $\mathrm{HBV}$ vaccine but not an $\mathrm{HCV}$ vaccine is notable for prevention strategies and the urgency to report a SI occurring in an environment with a high risk of exposure to $\mathrm{HCV}$.

Exposure to sharp injuries and mucocutaneous blood and body fluid splashes and splatters is a common occupational risk faced by HCWs. In emergencies and other urgent patient care events, it can be difficult for HCWs to use engineering controls and safer medical devices and to don personal protective equipment (PPE) in an urgent and timely manner. Therefore, it is critical that these devices and equipment are readily available and accessible so that HCWs have the opportunity to exercise good selfprotection. Research stated quite clearly that safety devices give impetus to the reduction of SIs $(8,26)$.

In summary, this study provides a good description and analysis of the status quo and risk factors for sharp injuries in HCWs in Shanghai and provides basic data for enhancing the occupational protection of HCWs. However, some limitations still exist in this study, Firstly, some data missing from our study cannot be further tracked, which may have resulted in a partial loss of results. Besides, we did not take into consideration the time after the beginning of the work the accident occurred. If it can be added to the follow-up study, we can alert HCWs in high-risk period to better pay attention to the sharp injuries (27). At the same time, we also noticed that training may greatly reduce sharp injuries. Therefore, research on interventions and the occurrence of sharp injuries will become a hot topic for us and other researchers in the future.

\section{Conclusions}

This study assesses the SIs and relevant risk factors of HCWs in Shanghai. Sharp injuries occur among HCWs in Shanghai dented optimism. There are multiple highrisk factors for SI and exposure to blood-borne pathogens in their work such as interns, general wards, disposable syringes, and lack of relevant training. HBV infection was the main source of exposure to sharp injuries. As such, medical institutions shall pay closer attention to this topic.

\section{Acknowledgments}

We are grateful for infection control practitioners at all participating hospitals for their hard work on collecting data and performing interviews. We appreciate the great support of the medical staff from Shanghai's 81 hospitals who participated in this survey. Because of their dedication, we can make it possible to promote a safer medical working environment. 
Funding: This work was supported by the 4th Three-year Action Plan for Public Health of Shanghai (15GWZK0101, 2015) and the Research project plan of Shanghai Municipal Commission of Health and Family Planning Funding (201640313, 2016).

\section{Footnote}

Conflicts of Interest: The authors have no conflicts of interest to declare.

Ethical Statement: The authors are accountable for all aspects of the work in ensuring that questions related to the accuracy or integrity of any part of the work are appropriately investigated and resolved. This study is a cross-sectional investigation confined only to the sharp injuries relevant information among HCWs only. It does not involve any collection of human or animal samples therefore do not involve ethics approval.

\section{References}

1. Belachew YB, Lema TB, Germossa GN, et al. Blood/Body Fluid Exposure and Needle Stick/Sharp Injury among Nurses Working in Public Hospitals; Southwest Ethiopia. Front Public Health 2017;5:299-305.

2. Lee JM, Botteman MF, Xanthakos N, et al. Needlestick injuries in the United States. Epidemiologic, economic, and quality of life issues. AAOHN J 2005;53:117-33.

3. Control CFD. Workbook for Designing, Implementing, and Evaluating a Sharps Injury Prevention Program. 2008.

4. Panlilio AL, Orelien JG, Srivastava PU, et al. Estimate of the annual number of percutaneous injuries among hospital-based healthcare workers in the United States, 1997-1998. Infect Control Hosp Epidemiol 2004;25:556-62.

5. Gao X, Hu B, Suo Y, et al. A large-scale survey on sharp injuries among hospital-based healthcare workers in China. Sci Rep 2017;7:42620.

6. Sharma R, Rasania S, Verma A, et al. Study of Prevalence and Response to Needle Stick Injuries among Health Care Workers in a Tertiary Care Hospital in Delhi, India. Indian J Community Med 2010;35:74-7.

7. Geravandia S, Alavic SM, Yarid AR, et al. Epidemiological Aspects of Needle Stick Injuries among Health Care Workers in Razi Hospital Ahvaz, Iran, in 2015. Arch Hyg Sci 2016;5:85-91.

8. Hoffmann C, Buchholz L, Schnitzler P. Reduction of needlestick injuries in healthcare personnel at a university hospital using safety devices. J Occup Med Toxicol 2013;8:20.

9. Azap A, Ergönül O, Memikoğlu KO, et al. Occupational exposure to blood and body fluids among health care workers in Ankara, Turkey. Am J Infect Control 2005;33:48-52.

10. Askarian M, Shaghaghian S, McLaws ML. Needlestick injuries among nurses of Fars province, Iran. Ann Epidemiol 2007;17:988-92.

11. Rajkumari N, Thanbuana BT, John NV, et al. A prospective look at the burden of sharps injuries and splashes among trauma health care workers in developing countries: true picture or tip of iceberg. Injury 2014;45:1470-8.

12. Garus-Pakowska A, Gorajski M, Szatko F. Did legal regulations change the reporting frequency of sharp injuries of medical personnel? Study from 36 hospitals in Lodz Province, Poland. Int J Occup Med Environ Health 2018;31:37-46.

13. Stawicki SP, Hoff W S, Hoey BA, et al. Human immunodeficiency virus infection in trauma patients: where do we stand? J Trauma 2005;58:88-93.

14. Kessler CS, McGuinn M, Spec A, et al. Underreporting of blood and body fluid exposures among health care students and trainees in the acute care setting: a 2007 survey. Am J Infect Control 2011;39:129-34.

15. Rapisarda V, Loreto C, Vitale E, et al. Incidence of sharp and needle-stick injuries and mucocutaneous blood exposure among healthcare workers. Future Microbiol 2019;14:27-31.

16. Musa S, Peek-Asa C, Young T, et al. Needle Stick Injuries, Sharp Injuries and other Occupational Exposures to Blood and Body Fluids among Health Care Workers in a general hospital in Sarajevo, Bosnia and Herzegovina. Int J Occup Saf Health 2014;4:31-7.

17. Goel V, Kumar D, Lingaiah R, et al. Occurrence of Needlestick and Injuries among Health-care Workers of a Tertiary Care Teaching Hospital in North India. J Lab Physicians 2017;9:20-5.

18. Dilie A, Amare D, Gualu T. Occupational Exposure to Needle Stick and Sharp Injuries and Associated Factors among Health Care Workers in Awi Zone, Amhara Regional State, Northwest Ethiopia 2016. J Environ Public Health 2017;2017:2438713.

19. Kasatpibal N, Whitney JD, Katechanok S, et al. Practices and impacts post-exposure to blood and body fluid in operating room nurses: A cross-sectional study. Int J Nurs 
Stud 2016;57:39-47.

20. Aziz AM. Do training and needle-safety devices prevent needlestick injuries? A systematised review of the literature. Br J Nurs 2018;27:944-52.

21. Adib-Hajbaghery M, Lotfi MS. Behavior of healthcare workers after injuries from sharp instruments. Trauma Mon 2013;18:75-80.

22. Afridi AA, Kumar A, Sayani R. Needle stick injuries--risk and preventive factors: a study among health care workers in tertiary care hospitals in Pakistan. Glob J Health Sci 2013;5:85-92.

23. Naghavi SH, Shabestari O, Alcolado J. Post-traumatic stress disorder in trainee doctors with previous needlestick injuries. Occup Med (Lond) 2013;63:260-5.

24. Zhang MX, Yu Y. A study of the psychological impact

Cite this article as: Lin J, Gao X, Cui Y, Sun W, Shen Y, Shi Q, Chen X, Hu B. A survey of sharps injuries and occupational infections among healthcare workers in Shanghai. Ann Transl Med 2019;7(22):678. doi: 10.21037/atm.2019.10.42 of sharps injuries on health care workers in China. Am J Infect Control 2013;41:186-7.

25. Goniewicz M, Wloszczak-Szubzda A, Niemcewicz M, et al. Injuries caused by sharp instruments among healthcare workers--international and Polish perspectives. Ann Agric Environ Med 2012;19:523-7.

26. Ghanei Gheshlagh R, Aslani M, Shabani F, et al. Prevalence of needlestick and sharps injuries in the healthcare workers of Iranian hospitals: an updated metaanalysis. Environ Health Prev Med 2018;23:44.

27. Ghannad MS, Majzoobi MM, Ghavimi M, et al. Needlestick and sharp object injuries among health care workers in Hamadan Province, Iran. J Emerg Nurs 2012;38:171-5. 
Table S1 Basic information regarding hospitals surveyed*

\begin{tabular}{lccccc}
\hline Type of hospital & $N$ & $\begin{array}{c}\text { Actual number of beds } \\
{\left[\mathrm{P}_{50}\left(\mathrm{P}_{25}, \mathrm{P}_{75}\right)\right]}\end{array}$ & $\begin{array}{c}\text { Annual outpatient visits } \\
{\left[\mathrm{P}_{50}\left(\mathrm{P}_{25}, \mathrm{P}_{75}\right)\right]}\end{array}$ & $\begin{array}{c}\text { Annual emergency room visits } \\
{\left[\mathrm{P}_{50}\left(\mathrm{P}_{25}, \mathrm{P}_{75}\right)\right]}\end{array}$ & $\begin{array}{c}\text { Annual number of inpatients } \\
{\left[\mathrm{P}_{50}\left(\mathrm{P}_{25}, \mathrm{P}_{75}\right)\right]}\end{array}$ \\
\hline Grade A tertiary & 19 & $877(729.5,1,289)$ & $142,911(108,154,238,974)$ & $13,496(6,728.5,37,513.5)$ & $4,054(2,706.5,7,227.5)$ \\
Grade B tertiary & 1 & $700(700,700)$ & $42378(42,378,42,378)$ & $6,983(6,983,6,983)$ & $3,153(3,153,3,153)$ \\
Grade A secondary & 38 & $622.5(419,821.75)$ & $61,610.5(30,717.75,12,6846)$ & $10,798(3,890.25,26,446.75)$ & $1,709(1,000.25,3,457.75)$ \\
Grade B secondary & 2 & $696.5(674.25,718.75)$ & $84,340.5(64,850.75,103,830.3)$ & $14,947.5(12,394.75,17,500.25)$ & $2,050(1,868.5,2,231.5)$ \\
Missing (hospitals & 21 & - & - & - & - \\
supplemented later) & & - & - & - & - \\
Total & 81 & - & & - & - \\
\hline
\end{tabular}

*, as the data on the basic information regarding hospitals surveyed were all non-normally distributed, the median and interquartile range P50 (P25, P75) was used to describe their distributions.

Table S2 Frequency of device types causing sharp injuries

\begin{tabular}{|c|c|c|c|c|c|c|c|c|c|c|}
\hline Job category & $\begin{array}{l}\text { Total number of SI } \\
\text { incidents per month }\end{array}$ & $\begin{array}{l}\text { Disposable } \\
\text { syringe (\%) }\end{array}$ & $\begin{array}{l}\text { Steel scalp } \\
\text { needle (\%) }\end{array}$ & $\begin{array}{l}\text { Surgical suture } \\
\text { needle (\%) }\end{array}$ & $\begin{array}{l}\text { Blood collection } \\
\text { needle }(\%)\end{array}$ & $\begin{array}{l}\text { n Surgical tool } \\
\text { (\%) }\end{array}$ & $\begin{array}{l}\text { Indwelling } \\
\text { needle (\%) }\end{array}$ & $\begin{array}{l}\text { Glass slide } \\
\text { (\%) }\end{array}$ & $\begin{array}{l}\text { Others } \\
(\%)\end{array}$ & $\begin{array}{l}\text { Missing } \\
\text { data (\%) }\end{array}$ \\
\hline Nurses & 660 & 237 (35.91) & $192(29.09)$ & $46(6.97)$ & $43(6.52)$ & $15(2.27)$ & $39(5.91)$ & $28(4.24)$ & $15(2.27)$ & $45(6.82)$ \\
\hline Doctors & 327 & 78 (23.85) & $35(10.7)$ & 111 (33.94) & $10(3.06)$ & 26 (7.95) & $4(1.22)$ & $7(2.14)$ & $33(10.09)$ & $23(7.03)$ \\
\hline $\begin{array}{l}\text { Logistical } \\
\text { workers }\end{array}$ & 31 & $14(45.16)$ & $5(16.13)$ & $3(9.68)$ & $0(0.00)$ & $5(16.13)$ & $0(0.00)$ & $1(3.23)$ & $3(9.68)$ & $0(0.00)$ \\
\hline $\begin{array}{l}\text { Medical } \\
\text { technicians }\end{array}$ & 46 & $20(43.48)$ & $6(13.04)$ & $0(0.00)$ & $6(13.04)$ & 7 (15.22) & $0(0.00)$ & $4(8.70)$ & $0(0.00)$ & $3(6.52)$ \\
\hline Interns & 4 & $1(25.00)$ & $1(25.00)$ & $0(0.00)$ & $0(0.00)$ & $0(0.00)$ & $0(0.00)$ & $0(0.00)$ & $0(0.00)$ & $2(50)$ \\
\hline Others & 72 & $16(22.22)$ & $34(47.22)$ & $1(1.39)$ & $11(15.28)$ & $1(1.39)$ & $1(1.39)$ & $1(1.39)$ & $7(9.72)$ & 0 \\
\hline Total & 1,140 & 366 (32.11) & 273 (23.95) & $161(14.12)$ & $70(6.14)$ & $54(4.74)$ & $44(3.86)$ & $41(3.60)$ & $58(5.09)$ & $73(6.40)$ \\
\hline
\end{tabular}

Table S3 Frequency of sharp injuries by length of service

\begin{tabular}{|c|c|c|c|c|c|c|c|c|}
\hline \multirow{2}{*}{ Job category } & \multirow{2}{*}{$\begin{array}{l}\text { Total number of } \\
\text { persons surveyed }\end{array}$} & \multicolumn{7}{|c|}{ Length of service (years) } \\
\hline & & $<5$ & 5-10 (inclusive) & 10-15 (inclusive) & 15-20 (inclusive) & 20-25 (inclusive) & 25-30 (inclusive) & $>30$ \\
\hline Nurses & 32,042 & $305(0.95)$ & $153(0.48)$ & $56(0.17)$ & $52(0.16)$ & $39(0.12)$ & $39(0.12)$ & $15(0.05)$ \\
\hline Doctors & 19,927 & $126(0.63)$ & $82(0.41)$ & $45(0.23)$ & $30(0.15)$ & $12(0.06)$ & $10(0.05)$ & $22(0.11)$ \\
\hline Logistical workers & 3,583 & $26(0.73)$ & $5(0.14)$ & $0(0.00)$ & $0(0.00)$ & $0(0.00)$ & $0(0.00)$ & $0(0.00)$ \\
\hline Medical technicians & 3,964 & $21(0.53)$ & $13(0.33)$ & $3(0.08)$ & $4(0.1)$ & $1(0.03)$ & $0(0.00)$ & $4(0.1)$ \\
\hline Interns & 1,458 & $51(3.50)$ & $2(0.14)$ & $1(0.07)$ & $1(0.07)$ & $0(0.00)$ & $0(0.00)$ & $0(0.00)$ \\
\hline Others & 316 & $3(0.95)$ & $1(0.32)$ & $0(0.00)$ & $0(0.00)$ & $0(0.00)$ & $0(0.00)$ & $0(0.00)$ \\
\hline Missing data & 19 & - & - & - & - & - & - & - \\
\hline Total & 61,309 & $532(0.87)$ & $256(0.42)$ & $105(0.17)$ & $87(0.14)$ & $52(0.08)$ & $49(0.08)$ & $41(0.07)$ \\
\hline
\end{tabular}

The incidence of sharp injuries to HCWs with different lengths of service = number of sharp injuries to HCWs with different lengths of service/total number of surveyed persons with that length of service $\times 100 \%$. 